\title{
Percutaneous nephrolithotomy versus open surgery for treatment of staghorn stones in pediatric patients
}

\author{
Ahmed R. El-Nahas, MD; Ahmed A. Shokeir, MD; Ahmed M. Shoma, MD; Ibrahim Eraky, MD; \\ Osama M. Sarhan, MD; Ashraf T. Hafez, MD; Mohamed S. Dawaba, MD; Ahmed M. Elshal, MD; \\ Ahmed M. Ghali, MD; Mahmoud R. El-Kenawy, MD
}

Mansoura Urology and Nephrology Center, Mansoura, Egypt

Cite as: Can Urol Assoc J 2014;8(11-12):e906-9. http://dx.doi.org/10.5489/cuaj.1994

Published online December 15, 2014.

\section{Abstract}

Introduction: We compare percutaneous nephrolithotomy (PCNL) and open surgery in the treatment of staghorn stones in children. Methods: We retrospectively reviewed the electronic records of children who underwent treatment for staghorn stones between September 2000 and August 2013. They were divided between Group 1 (patients who underwent PCNL) and Group 2 (patients who underwent open surgery). We compared stone-free and complications rates, need for multiple procedures, and hospital stay.

Results: The study included 41 patients ( 35 boys and 6 girls), with mean age $7.4 \pm 3.1$ years (range: $2-15$ ). Of these 41 patients, 26 had unilateral renal stone and 15 had bilateral renal stones. The total number of treated renal units was 56: 28 underwent PCNL and 28 underwent open surgery. The complication rate was comparable for both groups (32\% for open surgery vs. $28.6 \%, p=0.771$ ). Multiple procedures were more needed in PCNL group $(60.7 \%$ vs. $32 \%$ in open surgery, $p=0.032$ ). The stone-free rate was $71.4 \%$ after PCNL and $78.6 \%$ after open surgery $(p=0.537)$. A significant difference was observed in shorter hospital stay after PCNL (5 vs. 8.8 days, $p<0.001)$. Our study's limitations include its retrospective design and relatively small sample size.

Conclusions: For the treatment of staghorn stones in children, PCNL was comparable to open surgery in complication and stone-free rates. PCNL had the advantage of a shorter hospital stay and open surgery showed a decreased need for multiple procedures.

\section{Introduction}

Improvements in technology and experience have resulted in the acceptance of minimally invasive techniques to manage pediatric nephrolithiasis. ${ }^{1}$ Both extracorporeal shockwaves lithotripsy (SWL) and percutaneous nephrolithotomy $(\mathrm{PCNL})$ are safe and effective minimally invasive treatments of renal calculi in children. ${ }^{2}$ PCNL had been advocated as the preferred treatment for children with large stone burden to avoid numerous SWL sessions. Therefore, PCNL is the treatment of choice for pediatric renal calculi not suitable for SWL. ${ }^{3,4}$

Although PCNL is the first-line treatment for staghorn stones in adults, ${ }^{5}$ this is not the case for staghorn calculi in children. Concerns with PCNL in children include the use of large instruments in relation to the small kidney size, risk of major complications, and the long-term sequelae of renal punctures. ${ }^{1}$ However, advances in instruments and improvements in surgical techniques have increased the safety and efficacy of PCNL in children. There are reports of PCNL use for staghorn stones in children, ${ }^{6-9}$ but to the best of our knowledge, there are no studies comparing PCNL and open surgery.

In this study, we compared the results of PCNL and open surgery for the treatment of staghorn stones in children in terms of complications, stone-free rates, and need for multiple interventions.

\section{Methods}

We retrospectively reviewed the electronic records of children who underwent treatment of renal stones at our centre between September 2000 and August 2013. The study included patients with staghorn stones in the renal pelvis and branched to 2 major calices (partial staghorn) or branched to the 3 major calyces (complete staghorn).

Preoperative workup included serum creatinine estimation, urine culture, and complete blood count. Radiological evaluation included kidney, ureter, bladder (KUB), ultrasonography, and intravenous urography (IVU) or low-dose non-contrast computed tomography (NCCT). Preoperative urinary tract infections were treated with culture specific antibiotics for 5 days before surgical intervention. Other patients received intravenous third generation cephalosporins at the induction of anesthesia.

\section{Technique of percutaneous nephrolithotomy}

The cases were done by 5 experienced endourologists. Using general anesthesia and after placing a ureteral catheter, we 
placed the patient in the prone position. Percutaneous renal access was established by an experienced endourologist under multidirectional C-arm fluoroscopic guidance (BV Pulsera, Philips Medical Systems, Eindhoven, Netherlands). The skin was punctured at the posterior axillary line and the PCNL was completed in the same session. Dilation was performed using Alken's coaxial telescopic dilators (Karl Storz Endoskope, Tuttlingen, Germany). Tract size was decided by the operating endourologist depending on kidney size. Pneumatic lithotriptor was used for stone fragmentation. At the end of the procedure an 18 French $(F)$ nephrostomy tube was placed for 24 to 48 hours and no nephroureterotomy stents were left.

\section{Technique of open surgery}

Using general anesthesia, the patients were placed in the lateral position with a small roll under the waist. A lumbar, supracostal, extra-pleural and extra-peritoneal approach was used. After mobilization of the kidney, we retrieved the stones through extended pyelolithotomy or pyelonephrolithotomy. The pelvis was sutured with $4 / 0$ absorbable sutures, while the renal parenchyma was closed with $3 / 0$ sutures and the collecting system was drained with a nephro-ureterostomy stent for 7 days.

\section{Postoperative evaluation}

Low-dose NCCT was performed after 1 day. Post-PCNL residual stones were managed by second-look PCNL or SWL, according to the residual stone size and location. SWL was also used for residuals after open surgery. Stone-free status was re-evaluated after 3 months for patients who required SWL. Stone-free was defined as complete clearance of the stones. Renal function changes were evaluated with nuclear renography comparing glomerular filtration rate (GFR) percent during follow-up with the preoperative values. Changes $>5 \%$ were considered for improvement or decline of the GFR percent.

\section{Statistical analysis}

The data were analyzed using SPSS (SPSS Inc., Chicago, IL). Categorical variables (stone-free, complications rates, need for multiple procedures) were compared using Chi-square or Fisher's exact test, while continuous variables (hospital stay) were compared using independent sample t-test. A $p<0.05$ was considered statistically significant.

\section{Results}

Treatment of staghorn stones in children was reported in 48 patients. We excluded 4 patients with stones branching to 1 major calyx and 3 patients with giant staghorn stones.
In total, we included 41 patients ( 35 boys and 6 girls), with mean age $7.4 \pm 3.1$ years (range: $2-15$ ). Of these 41 patients, 26 had unilateral renal stone and 15 had bilateral renal stones. The total number of treated renal units was 56: 28 underwent PCNL and 28 underwent open surgery. No simultaneous procedures were performed.

\section{Group 1: PNCL}

Of the total 28 renal units in the PCNL group, 1 tract was needed in 14 renal units $(50 \%), 2$ tracts were needed in 13 units, and 3 tracts were required in 1 unit. Supracostal punctures were required in 11 cases (39\%). In 13 cases, an Amplatz sheath of $30 \mathrm{~F}$ was placed which allowed us to use adult instruments. In 15 cases (53.6\%), a 24F Amplatz sheath was placed and a pediatric nephroscope was used (Richard Wolf, Knittingen, Germany). The 24F Amplatz sheath was also used in patients who required secondary tracts. A flexible nephroscope was used to retrieve stone fragments that escaped to a calyx away from the tract. Second-look PCNL was needed in 9 cases.

All PCNL were completed successfully with no intraoperative complications. Postoperative complications developed after 8 procedures $(28.6 \%)$. They included hematuria which required blood transfusion in 4 cases, urinary leakage through the tract in 2 and fever in 2.

Secondary procedures included SWL in 6 cases, ureteroscopy for retrieval of obstructing ureteral stone causing urinary leakage in 1 case, and a double-J stent to control urinary leakage without calcular obstruction in 1 case. The stone-free rate at 3 months was $71.4 \%$; 20 renal units were stone-free and 8 units had insignificant residual fragments $<4 \mathrm{~mm}$ at 3 months.

\section{Group 2: Open surgery}

For open surgeries, cold renal ischemia was needed in 8 patients for 15 to 60 minutes. Complications were encountered in 9 cases $(32 \%)$. Intraoperative pleural injury in 1 case was repaired without intercostal chest tube. Another patient suffered from bleeding during nephrolithotomy that necessitated blood transfusion. Five patients developed postoperative fever $\left(>38^{\circ} \mathrm{C}\right) ; 4$ were successfully treated with antibiotics and antipyretics, while 1 patient had ipsilateral lung collapse due to unnoticed pleural injury. He was managed with a chest tube. Wound infection developed in 1 case, which was treated with adequate wound care, while urinary leakage was treated with a double-J stent in another patient.

Secondary procedures included SWL in 6 cases, ureteroscopy for stone slipped to the ureter in 1 case and a double-J for urinary leakage in another case. The stone-free rate at 3 months was $78.6 \%$; 22 renal units were stone-free and 6 had insignificant residuals at 3 months. 


\section{Comparing both groups}

Statistically significant differences were observed for more multiple procedures and the shorter hospital stay among patients who underwent PCNL (Table 1).

The median follow-up was 24 months (range: 12-66). There were comparable follow-up results between both groups (Table 2). Two cases experienced a decline in renal function by $9 \%$ and $7 \%$ open surgery. After PCNL, a decline in renal function by $9 \%$ was observed in 1 case.

\section{Discussion}

The safety and efficacy of PCNL for staghorn stones have been well-established in adults. ${ }^{5}$ Concerns about PCNL in children include small kidneys, possible deleterious effects on renal function, and the risk of major complications, including sepsis and bleeding. ${ }^{10}$ Changes in technique and instrumentation have changed the management of pediatric stone disease. Therefore, PCNL is increasingly being used as

\begin{tabular}{|c|c|c|c|}
\hline Variable & $\begin{array}{l}\text { Open surgery } \\
\text { (28 units) N (\%) }\end{array}$ & $\begin{array}{c}\text { PCNL } \\
\text { (28 units) N (\%) }\end{array}$ & $p$ value \\
\hline \multicolumn{4}{|l|}{ Side: } \\
\hline Right & $14(50)$ & $14(50)$ & 1 \\
\hline Left & $14(50)$ & $14(50)$ & \\
\hline Past stone treatment & $3(10.7)$ & $6(21.4)$ & 0.275 \\
\hline Hydronephrosis & $23(82)$ & $26(92.9)$ & 0.225 \\
\hline \multicolumn{4}{|l|}{ Staghorn burden: } \\
\hline Complete & $22(78.6)$ & 22 (78.6) & 1 \\
\hline Partial & $6(21.4)$ & $6(21.4)$ & \\
\hline $\begin{array}{l}\text { UTI (infected urine } \\
\text { culture) }\end{array}$ & $15(53.6)$ & $9(32)$ & 0.105 \\
\hline $\begin{array}{l}\text { Complications } \\
\text { Modified Clavien }\end{array}$ & $9(32)$ & $8(28.6)$ & \\
\hline \multicolumn{4}{|l|}{ Classification: } \\
\hline Grade I & 3 & 4 & 0.771 \\
\hline Grade II & 1 & 2 & \\
\hline $\begin{array}{l}\text { Grade IIla } \\
\text { Grade IVb }\end{array}$ & 1 & 0 & \\
\hline Blood transfusion & $1(3.6)$ & $4(14.3)$ & 0.160 \\
\hline $\begin{array}{l}\text { Secondary } \\
\text { procedures }\end{array}$ & $8(28.6)$ & $8(28.6)$ & 1 \\
\hline Multiple procedures & $9(32)$ & $17(60.7)$ & 0.032 \\
\hline \multirow[t]{2}{*}{$\begin{array}{l}\text { Stone-free rate at } 3 \\
\text { months }\end{array}$} & $22(78.6)$ & $20(71.4)$ & 0.537 \\
\hline & Mean (SD) & Mean (SD) & \\
\hline Age (years) & $7.6(3.31)$ & $7.1(2.93)$ & 0.525 \\
\hline Serum creatinine & $0.7(0.33)$ & $0.5(0.14)$ & 0.010 \\
\hline $\begin{array}{l}\text { Hemoglobin deficit } \\
\text { (g/dL) }\end{array}$ & $1.5(0.57)$ & $1.55(0.77)$ & 0.785 \\
\hline Hospital stay (days) & $8.8(4.1)$ & $5(2.3)$ & $<0.001$ \\
\hline
\end{tabular}

monotherapy or in combination with SWL to treat staghorn stones in children. ${ }^{11}$

Aron and colleagues found complete clearance of staghorn stones in $89 \%$ of preschool children using PCNL. ${ }^{8}$ Kumar and colleagues reported stone clearance in $92 \%$ of pediatric patients with staghorn stones. ${ }^{9}$ However, Aron and colleagues evaluated the clearance rate with KUB for radioopaque stones and ultrasound for lucent stones; ${ }^{8}$ Kumar and colleagues used intraoperative fluoroscopy and KUB on the first postoperative day. ${ }^{9}$ The clearance rate after $\mathrm{PCNL}$ in our patients was $71.4 \%$ because we evaluated stone-free rates after PCNL with NCCT - this is more sensitive than KUB and ultrasound in detecting residual fragments. ${ }^{12}$ We determined treatment success using stone-free rates because any size of stone fragment in a young stone former may require repeat surgical procedures. ${ }^{13}$

The complication rate of $28.6 \%$ among our patients was comparable to the recently published results. ${ }^{14,15}$ Guven and colleagues concluded that complications were comparable to those seen in adults provided there surgeons have enough experience with the technique. Therefore, we recommend PCNL for staghorn stones in children at tertiary care centres with experienced surgeons. ${ }^{16}$

The issue of renal function affection after PCNL in children was investigated by Dawaba and colleagues using radio-isotope renal scans. The authors observed a decline in renal function in 1 of their 72 renal units. They also found no renal scarring at follow-up. ${ }^{17}$ However, they included all cases of PCNL in children. In our patients, a decline in renal function by $9 \%$ was observed after PCNL for staghorn stones in 1 of our $18(5.6 \%)$ renal units.

For open surgery, anatrophic nephrolithotomy has been shown to cause significant deterioration in renal function in 5 out of 9 children after surgery and this decline ranged from $6 \%$ to $16 \% .^{18}$ This may be related to the effect of renal ischemia during surgery. Among our patients, a decline in renal function by $9 \%$ and $7 \%$ were observed in 2 of 15 $(13.3 \%)$ renal units after open surgery despite excluding

Table 2. Results of follow-up after open surgery and PCNL for the treatment of staghorn stones in children

\begin{tabular}{lccc}
\hline Variable & $\begin{array}{c}\text { Open surgery } \\
\text { N (\%) }\end{array}$ & $\begin{array}{c}\text { PCNL } \\
\text { N (\%) }\end{array}$ & p value \\
\hline Condition at last follow-up: & 16 Units & 27 Units & \\
Stone-free & $8(50)$ & $15(55.6)$ & $0.724^{\&}$ \\
Stone recurrence & $8(50)$ & $12(44.4)$ & \\
Treatment at follow-up: & 16 Units & 27 Units & \\
No treatment & $8(50)$ & $15(55.6)$ & $0.764^{*}$ \\
SWL & $4(25)$ & $4(14.8)$ & \\
PNL & $4(25)$ & $8(29.6)$ & \\
Renal function changes: & 15 Units & 18 Units & \\
Stable & $10(66.7)$ & $11(61)$ & $0.657^{*}$ \\
Improved & $3(20)$ & $6(33.4)$ & \\
Declined & $2(13.3)$ & $1(5.6)$ & \\
\hline \&Chi-square test; *Fisher's exact test; N: Number of renal units & & \\
\hline
\end{tabular}


Open surgery vs. PCNL for staghorn stones in children

patients with giant staghorn stones who would have required anatrophic nephrolithotomy.

Another concern about PCNL in children was the use of adult instruments for their small kidneys. Dogan and colleagues found that in children with high-stone burden, the use of adult-type instruments may positively affect their stone-free rate and operation time without increasing their complication rate. ${ }^{19}$ Although we used adult instruments in about half of our PCNL cases with no major complications, we think that the use of newer miniaturized nephroscopes and laser lithotripsy through smaller tracts may be safer for younger children. This hypothesis needs to be demonstrated in future large-scale studies.

In our present study, comparable stone-free rates were observed for open surgery and PCNL. Bayrak and colleagues reported comparable stone-free rates of PCNL and open surgery for pediatric stones. ${ }^{20}$ Another important finding was the observation of comparable complication rates. All complications could be successfully managed without damaging the kidney. The complexity and large stone burden of staghorn stones necessitated the use of multiple tracts or multiple open nephrolithotomies. Ozden and colleagues reported the need for multiple tracts in $40 \%$ of the $53 \mathrm{PCNL}$ performed for complex renal calculi.7 They also reported a mean hemoglobin decrease of $1.6 \mathrm{~g} / \mathrm{dL}$. Similar results were observed in our patients as multiple tracts were needed in $50 \%$ and the mean hemoglobin decrease was $1.5 \mathrm{~g} / \mathrm{dL}$.

Other important findings of our study include the statistically significant shorter hospital stay after PCNL compared with open surgery ( 5 vs. 8.8 days). On the other hand, open surgery had the advantage of a lesser need for multiple procedures (32\% vs. $60.7 \%$ in the PNL group). This is very helpful information when we counsel parents about the treatment options. Parents should know that PCNL is a safe and effective minimally invasive treatment when compared with open surgery, but multiple interventions may be needed in $60 \%$ of cases.

Our study has its limitations, including its retrospective design that may have affected the allocation of patients to each treatment groups; moreover, endourologists may be biased towards the PCNL approach and pediatric urologic surgeons towards open surgery. Another limitation is the relatively small sample size that may have jeopardized our statistical analysis. These limitations can be overcome in the future by conducting multicentre, randomized studies.

\section{Conclusion}

PCNL was comparable to open surgery for the treatment of pediatric staghorn stones in terms of complications and stone-free rates. However, PCNL had the advantage of shorter hospital stay and open surgery showed a lesser need for multiple procedures.
Competing interests: Authors declare no competing financial or personal interests.

This paper has been peer-reviewed.

\section{References}

1. Desai M. Endoscopic management of stones in children. Cur Opin Urol 2005;15:107-12. http://dx.doi. org/10.1097/01.mou.0000160625.59107.fd

2. Shokeir AA, Sheir KZ, El-Nahas AR, et al. Treatment of renal stones in children: A comparison between percutaneous nephrolithotomy and shock wave lithotripsy. J Urol 2006;176:706-10. http://dx.doi. org/10.1016/i.juro.2006.03.080

3. Samad L, Aquil S, Zaidi Z. Paediatric percutaneous nephrolithotomy: Setting new frontiers. BJU Int 2006;97:359-63. http://dx.doi.org/10.1111/i.1464-410X.2006.05932.x

4. Bilen CY, Koasak B, Kitirci $G$, et al. Percutaneous nephrolithotomy in children: Lessons learned in 5 years at a single institution. J Urol 2007;177:1867-71. http://dx.doi.org/10.1016/i.juro.2007.01.052

5. Preminger GM, Assimos DG, Lingeman JE, et al. AUA guideline on management of staghorn calculi: Diagnosis and treatment recommendations. J Urol 2005;173:1991-2000. http://dx.doi.org/10.1097/01. ju.0000161171.67806.2a

6. Desai MR, Kukreja RA, Patel SH, et al. Percutaneous nephrolithotomy for complex pediatric renal calculus disease. J Endourol 2004; 18:23-7. http://dx.doi.org/10.1089/089277904322836613

7. Ozden $E$, Sahin $A$, Tan $B$, et al. Percutaneous renal surgery in children with complex stones. J Pediatr Urol 2008;4:295-8. http://dx.doi.org/10.1016/i.jpurol.2008.01.212

8. Aron $M$, Yadav R, Goel R, et al. Percutaneous nephrolithotomy for complete staghorn calculi in preschool children. J Endourol 2005;19:968-72. http://dx.doi.org/10.1089/end.2005.19.968

9. Kumar R, Anand A, Saxena V, et al. Safety and efficacy of PCNL for management of staghorn calculi in pediatric patients. J Pediatr Urol 2011;7:248-51. http://dx.doi.org/10.1016/i.jpurol.2011.02.016

10. Rizvi SA, Naqui SA, Hussain Z, et al. Management of pediatric urolithiasis in Pakistan: Experience with 1,440 children. J Urol 2003;169:634-7. http://dx.doi.org/10.1016/S0022-5347(05)63979-1

11. Horuz R, Sarica K. The management of staghorn calculi in children. Arab J Urol 2012;10:330-5. http:// dx.doi.org/10.1016/i.aju.2012.03.005

12. Osman Y, EL-Tabey N, Refai H, et al. Detection of residual stones after percutaneous nephrolithotomy: Role of non-enhanced spiral computerized tomography. J Urol 2008;179:198-200. http://dx.doi. org/10.1016/i.juro.2007.08.175

13. Afshar K, McLorie G, Papanikolaou F, et al. Outcome of small residual stone fragments following shock wave lithotripsy in children. J Urol 2004;172:1600-3. http://dx.doi.org/10.1097/01. ju.0000138525.14552.1b

14. Ganpule AP, Mishra S, Desai MR. Percutaneous nephrolithotomy for pediatric urolithiasis. Indian I Urol 2010;26:549-54. http://dx.doi.org/10.4103/0970-1591.74458

15. Guven $\mathrm{S}$, Istanbulluoglu 0 , Gul U, et al. Successful percutaneous nephrolithotomy in children: Multicenter study on current status of its use, efficacy and complications using Clavien classification. I Urol 2011;185:1419-24. http://dx.doi.org/10.1016/i.juro.2010.11.055

16. El-Nahas AR, Eraky I, Shokeir AA, et al. Percutaneous nephrolithotomy for treating staghorn stones: 10 years of experience of a tertiary-care centre. Arab J Urol 2012;10:324-9. http://dx.doi.org/10.1016/i. aju.2012.03.002

17. Dawaba MS, Shokeir AA, Hafez AT, et al. Percutaneous nephrolithotomy in children: Early and late anatomical and functional results. J Urol 2004;172:1078- 81. http://dx.doi.org/10.1097/01. ju.0000134889.99329.f7

18. Gough DCS, Baillie CT. Paediatric anatrophic nephrolithotomy: Stone clearance at what price? BJU Int 2000;85:874-8. http://dx.doi.org/10.1046/i.1464-410x.2000.00626.x

19. Dogan $B$, Atmaca AF, Canda AE, et al. Efficiency of percutaneous nephrolithotomy in pediatric patients using adult-type instruments. Urol Res 2012;40:259-62. http://dx.doi.org/10.1007/s00240-011-0408-4

20. Bayrak 0 , Seckiner I, Erturhan $\mathrm{S}$, et al. Comparative analyses of percutaneous nephrolithotomy versus open surgery in pediatric urinary stone disease. Pediatr Surg Int 2012;28:1025-9. http://dx.doi. org/10.1007/s00383-012-3130-6

Correspondence: Dr. Ahmed R. El-Nahas, Assistant Professor of Urology, Mansoura Urology and Nephrology, Center, Mansoura, Egypt; ar_el_nahas@yahoo.com 